\title{
GERMINAÇÃO DE SEMENTES E EMERGÊNCIA DE PLÂNTULAS DE Oenocarpus minor Mart. (ARECACEAE) ${ }^{1}$
}

\author{
BRENO MARQUES DA SILVA E SILVA², FABIANO CESARINO ${ }^{3}$, JULIANA DOMINGOS LIMA4, \\ TAMMYA DE FIGUEIREDO PANTOJA 5 , FABIOLA VITTI MÔRO 6
}

\begin{abstract}
RESUMO - O presente trabalho teve como objetivo avaliar a influência da temperatura e do substrato na germinação, bem como determinar a profundidade ideal de semeadura para emergência de plântulas de Oenocarpus minor Mart. Utilizou-se o delineamento experimental inteiramente casualizado, em esquema fatorial 3x4 (temperatura x substrato), com três repetições de 30 sementes cada. As sementes foram colocadas no interior de caixas plásticas contendo substrato umedecido com água destilada e mantidas em câmaras de germinação à temperatura constante e com fotoperíodo de 12 horas. Para a emergência, foram usadas 4 repetições de 24 sementes, distribuídas em bandeja plásticas, com plantmax e vermiculita, em 0; 2 e $4 \mathrm{~cm}$ de profundidade de semeadura, mantidas em casa de vegetação. Baseado nos resultados obtidos, os substratos mais adequados para a germinação de sementes foram a areia e a vermiculita, e a melhor temperatura foi a de $30^{\circ} \mathrm{C}$. Profundidade superior a $2 \mathrm{~cm}$ é inadequada para a semeadura de Oenocarpus minor Mart.
\end{abstract}

Termos para indexação: bacabinha, palmeiras, germinação, emergência.

\section{GERMINAÇÃo DE SEMENTES E EMERGÊNCIA DE PLÂNTULAS DE Oenocarpus minor Mart. ARECACEAE)}

ABSTRACT - (Seed Germination Of Oenocarpus minor Mart. in Different Substrata And Temperatures). The present work had as objective to evaluate the influence of the temperature and the substratum in the germination, thus as to determine the ideal depth of sowing for emergency of Oenocarpus minor Mart. seedlings. The experimental design was completely randomized, arranged in a 3x4 factorial scheme (temperature $\mathrm{x}$ substrate), with three replications of 30 seeds each. The seeds were placed in plastic boxes containning substratum and incubated at constant temperature in a germination chambers at constant temperature and $12 \mathrm{~h}$ photoperiod. For the emergency, 4 replications of 24 seeds had been used, distributed in tray plastic, with plantmax and vermiculita, in 0,2 and $4 \mathrm{~cm}$ of sowing depth and kept in greenhouse. Based in results the best substrates and temperature for germination of Oenocarpus bacaba Mart. was sand and vermiculite and temperature of $30^{\circ} \mathrm{C}$, respectively. Depths superior than $2 \mathrm{~cm}$ are inadequate for sowing of Oenocarpus minor Mart.

Index terms: bacabinha, bacabi, palm, germinative button

\section{INTRODUÇÃO}

AAmazônia possui valioso reservatório de recursos genéticos de espécies frutíferas (Calzavara, 1978). Todavia, a vegetação natural vem sendo suprimida para dar lugar à expansão, principalmente das fronteiras agropecuárias, onde, na maioria das vezes, novas áreas são abertas, seja por esgotamento dos solos, seja ou pela necessidade de maior produção (Silva et al., 2003). Da mesma forma, a exploração desordenada dos recursos naturais tem gerado a degradação de áreas em quase todo o território nacional (Ferreira, 2000).

No entanto, a maioria das espécies amazônicas ainda é pouco conhecida quanto ao potencial de exploração econômica e sua contribuição para o bem-estar humano, assim como na economia nacional (Clement et al., 1982). Desta forma, para proporcionar o aproveitamento do potencial econômico das palmeiras regionais e a incorporação à lista de produtos comerciais, torna-se necessária a ampliação dos estudos básicos e aplicados para um melhor conhecimento de sua diversidade, ocupação no ecossistema, evolução, adaptação e desenvolvimento de métodos adequados para o manejo e utilização de seu potencial (Miranda et al., 2001).

Oenocarpus minor Mart., conhecida popularmente por bacabinha ou bacabi, é uma palmeira multicaule com aproximadamente 8 metros de altura e cerca de $7 \mathrm{~cm}$ de diâmetro, com inflorescência intrafoliar e frutos globosos-elipsóides lisos, medindo 2,1 x 1,8cm de diâmetro, de coloração roxo-escura quando maduros (Henderson \& Scariot, 1993; Miranda et al., 2001). Tradicionalmente, as sementes são usadas para obtenção de óleo, o estipe para confecção de moradias, o palmito para a alimentação e dos frutos é extraído um vinho bastante semelhante ao de Euterpe oleracea Mart.. Além disso, por causa de suas características morfológicas, essa espécie possui, ainda, grande potencial para o paisagismo e a ornamentação (Lorenzi et al., 1996; Paula \& Alves, 1997; Miranda et al., 2001).

Estudos sobre a influência da temperatura na germinação das sementes são essenciais para entender os aspectos ecofisiológicos e bioquímicos (Labouriau, 1983; Bewley \& Black, 1994). Para compreender os efeitos da temperatura sobre a germinação, podem ser avaliadas mudanças ocasionadas na percentagem, velocidade de germinação ao longo do tempo (Labouriau \& Pacheco, 1978), sendo que a faixa de temperatura ótima é aquela onde ocorre a germinação máxima no menor tempo médio (Labouriau, 1983).

A emergência das plântulas depende não só da energia contida no endosperma ou cotilédones, mas também da profundidade em que a semente é semeada (Hackbart \& Cordazzo, 2003).

Uma germinação rápida e uniforme das sementes, seguida por imediata emergência das plântulas são características altamente desejáveis na formação de mudas, pois quanto mais tempo a plântula permanecer nos estádios iniciais de desenvolvimento e demorar para emergir do solo, mais vulnerável estará às condições adversas do meio (Martins et al., 1999).

A bacabinha necessita de estudos básicos para subsidiar sua domesticação, uso racional, bem como a produção de mudas de alta qualidade para diversos fins. Desta forma, o presente trabalho teve como objetivo determinar o substrato, a temperatura e a profundidade de semeadura mais adequados para a germinação de

\footnotetext{
${ }^{1}$ (Trabalho 026-2006). Recebido: 13-03-2006. Aceito para publicação: 30-05-2006.

${ }^{2}$ Bolsista de Mestrado do CNPq - Mestrado em Agronomia (Produção e Tecnologia de Sementes) - Universidade Estadual Paulista (Unesp) - Faculdade de Ciências Agrárias e Veterinárias (FCAV) - Campus Jaboticabal. Rua Brasília, 700, Bloco C, Apto. 303. 14883-260, Bairro Vila Industrial. Jaboticabal-SP. email: silvabms@yahoo.com.br.

${ }^{3}$ Dr. Pesquisador - Laboratório de Sementes e Mudas do Instituto de Pesquisa Científicas e Tecnológicas do Estado do Amapá (IEPA). E-mail: fabianocesarino@yahoo.com.br.

${ }^{4}$ Mestranda em Agronomia (Genética e Melhoramento de Plantas) - FCAV/Unesp-SP. e-mail: tammyapantoja@hotmail.com.

${ }^{5}$ Dra. Docente - Unidade Diferenciada de Registro - Unesp. E-mail: judlima@ registro.unesp.br

${ }^{6}$ Prof $^{a}$. Dra. Unesp/FCAV/DBAA - Departamento de Biologia Aplicada à Agropecuária. E-mail: fabiola@fcav.unesp.br
} 
sementes de Oenocarpus minor Mart.

\section{MATERIAL E MÉTODOS}

As sementes de Oenocarpus minor Mart. foram coletadas diretamente das palmeiras localizadas na Fazenda Esperança, no Distrito de São Joaquim do Pacuí, em Macapá - AP, Brasil. Os frutos foram enviados para o Laboratório de Sementes do Instituto de Pesquisas Científicas e Tecnológicas do Estado do Amapá - IEPA, para análise das sementes.

$\mathrm{O}$ processo de beneficiamento dos frutos para obtenção das sementes consistiu em submergi-los em água morna (cerca de $47^{\circ} \mathrm{C}$ ) durante 15 minutos e posterior retirada manual do pericarpo. A assepsia das sementes foi realizada por meio da aplicação de benomyl $0,1 \%$ durante 10 minutos, seguida de lavagem em água corrente por 5 minutos.

O teor de água do lote de sementes foi determinado com 4 repetições de 10 sementes, em estufa a $105^{\circ} \mathrm{C}$, durante 24 horas, conforme as Regras de Análise de Sementes (Brasil, 1992).

Para o teste de germinação, foram utilizadas três repetições de 30 sementes, distribuídas em caixas plásticas contendo os substratos, vermiculita, plantmax, areia ou papel-filtro, mantidas em germinadores, com fotoperíodo de 12 horas e nas temperaturas constantes de $25 ; 30$ e $35^{\circ} \mathrm{C}$.

Para o teste de emergência, foram utilizadas 4 repetições de 24 sementes, distribuídas em bandeja plásticas, com uma mistura de iguais proporções de Plantmax e vermiculita, em 0;2 e $4 \mathrm{~cm}$ de profundidade de semeadura, mantidas em casa de vegetação $(30 \pm$ $5^{\circ} \mathrm{C}$ ) com sombreamento de $50 \%$.

Para avaliar a influência da temperatura e do substrato, foi adotado como critério de germinação a protrusão da raiz primária de e"0,5cm (Bewley \& Black, 1994), enquanto para a emergência, o crescimento de e" $1 \mathrm{~cm}$ do coleóptilo acima do substrato. Posteriormente, foram calculados as porcentagens e os tempos médios de germinação conforme Labouriau \& Agudo (1987).

Decorridos 60 dias após a semeadura, aleatoriamente, em 3 repetições de 20 plântulas por tratamento, foram realizadas mensurações de altura, diâmetro do colo e massa de matéria seca das plântulas, de acordo com os procedimentos realizados por Clement \& Bovi (1992) e Benincasa (2003)

O delineamento experimental foi o inteiramente casualizado, em esquema fatorial $3 \times 4$, sendo 3 temperaturas e 4 substratos. Os dados de porcentagem de germinação foram transformados em arcosen $(\%)^{0,5}$, porém, na Tabela, foram apresentadas as médias originais. As comparações entre as médias foram feitas mediante a aplicação do teste de Tukey, ao nível de 5\% de probabilidade (Gomes, 1987).

\section{RESULTADOS E DISCUSSÕES}

O teor médio de água do lote de semente de Oenocarpus. minor Mart. foi de 46,5\% ( $\pm 4,34 \%)$, semelhante ao alto teor de água (45\%) observado em Bactris gasipaes Kunth, segundo Ferreira \& Santos (1993).

Não houve interação significativa entre substrato e temperatura para a porcentagem e o tempo médio de germinação de $O$. minor, apenas efeito isolado desses fatores. Quanto ao comportamento germinativo, a interação significativa entre temperatura e substrato de sementes foi verificada por Figliolia et al. (1993). No entanto, Andrade et al. (1999) e Iossi et al. (2003), trabalhando também com palmeiras, não encontraram interação significativa entre substrato e temperatura para porcentagem de germinação.

Não houve diferenças nas porcentagens de germinação de sementes de bacabinha nos diferentes substratos testados (Tabela $1)$.

As sementes de bacabinha possuem boa plasticidade em relação ao substrato, pois conseguiram adequar sua germinação à
TABELA 1 - Porcentagem de germinação média de sementes de Oenocapus minor Mart. em diferentes substratos e temperaturas.

\begin{tabular}{lcccc}
\hline & \multicolumn{4}{c}{ Temperatura $\left({ }^{\mathbf{0}} \mathbf{C}\right) *$} \\
\cline { 2 - 5 } Substratos* & $\mathbf{2 5}$ & $\mathbf{3 0}$ & $\mathbf{3 5}$ & Média \\
\hline Papel & 96,67 & 93,34 & 0 & $64,34 \mathrm{a}$ \\
Areia & 96,67 & 98,89 & 0 & $65,19 \mathrm{a}$ \\
Vermiculita & 97,78 & 100 & 0 & $65,93 \mathrm{a}$ \\
Plantmax & 97,78 & 100 & 0 & $65,93 \mathrm{a}$ \\
\hline Média & $97,22 \mathrm{~A}$ & $98,06 \mathrm{~A}$ & $0 \mathrm{~B}$ & 65,09 \\
\hline
\end{tabular}

* Médias seguidas de mesma letra, maiúsculas nas linhas e minúsculas nas colunas, não diferem entre si, pelo teste de Tukey, ao nível de 5\% de probabilidade.

variação deste fator. Sementes de Phoenix roebelenii O'Brien apresentaram comportamento semelhante em relação à germinação quando os substratos utilizados foram esfagno, serragem, areia e vermiculita (Iossi et al., 2003). Por outro lado, sementes de Bactris gasipaes Kunth germinaram melhor em areia (Ledo et al., 2002) que em vermiculita, enquanto sementes de Euterpe edulis Mart. tiveram maior porcentagem de germinação em vermiculita (Souza et al., 1995).

A germinação nas temperaturas de 25 e $30^{\circ} \mathrm{C}$ foi semelhante e maior do que a $35^{\circ} \mathrm{C}$ (Tabela 1 ). As sementes de Phoenix roebelenii $\mathrm{O}^{\prime}$ Brien apresentaram porcentagens de germinação semelhantes quando germinadas em 25 e $30^{\circ} \mathrm{C}$ (Iossi et al., 2003).

As sementes de $O$. minor não germinaram a $35^{\circ} \mathrm{C}$. Portanto, a temperatura máxima de germinação para sementes de $O$. minor está entre 31 e $35^{\circ} \mathrm{C}$. Sementes de Phoenix roebelenii O’Brien (Iossi et al., 2003) possuem germinação praticamente nula apenas a partir de $40^{\circ} \mathrm{C}$.

De modo geral, no processo de germinação de sementes de palmeiras, destacam-se três eventos: a formação do botão germinativo, a protrusão da raiz primária e a formação de plântula normal (Tomlinson, 1961; Pinheiro, 1986). A emissão do botão germinativo como critério de germinação foi proposta por Queiroz (1986) em estudos realizados em sementes de Euterpe edulis Mart.. De acordo com este critério, para as sementes de $O$. mino em diferentes substratos, observou-se a formação de botão germinativo em cerca de $46 \% \pm 2.6$ das sementes, a $35^{\circ} \mathrm{C}$. Entretanto, não houve, posteriormente, protrusão da raiz primária. Durante o processo germinativo das sementes de bacabinha, o aparecimento de necrose no ápice do botão germinativo foi generalizado, ao ponto de inviabilizar o crescimento da raiz primária.

Resultados semelhantes foram observados em estudos sobre germinação de Euterpe edulis Mart, que apresentou emissão da raiz primária a $35^{\circ} \mathrm{C}$, porém sem a subseqüente formação da plântula (Andrade et al., 1999).

De acordo com Lorenzi et al. (1996), a germinação de sementes de várias espécies de palmeiras é favorecida por temperaturas entre $24^{\circ} \mathrm{C}$ e $28^{\circ} \mathrm{C}$ e umidade relativa do ar de aproximadamente $70 \%$.

Provavelmente, há diferentes exigências de temperatura de germinação entre tais eventos (botão germinativo, raiz primária e plântula), podendo ainda variar de acordo com diferentes estresses ambientais. Em virtude disso, é essencial estabelecer um critério ideal para a germinação das diferentes espécies de palmeiras.

Os substratos possuem diferentes níveis de disponibilidade de água de acordo com suas características físicas (Figliolia \& PiñaRodrigues, 1995). Desta forma, essas características podem ter influenciado a velocidade da embebição e, por conseguinte, a velocidade de germinação. Observou-se que os menores tempos médios de germinação de sementes de $O$. minor ocorreram em areia e vermiculita (Tabela 2), contrariamente ao que foi obtido para sementes de Bactris gasipaes Kunth em que a germinação foi mais rápida em areia (Ledo et al., 2002) e de Euterpe edulis Mart., mais rápida em vermiculita (Souza et al., 1995)..

O maior tempo para germinação de sementes $O$. minor ocorreu quando se utilizou papel-filtro e plantmax como substrato 
TABELA 2 - Tempo médio de germinação de sementes de Oenocarpus minor Mart. em diferentes substratos e temperaturas.

\begin{tabular}{lcccl}
\hline & \multicolumn{4}{c}{ Temperatura - T $\left({ }^{\circ} \mathbf{C}\right) *$} \\
\hline Substratos - S* & $\mathbf{2 5}$ & $\mathbf{3 0}$ & $\mathbf{3 5}$ & Média \\
\hline Areia & 16,04 & 13,53 & - & $14,78 \mathrm{a}$ \\
Vermiculita & 17,14 & 13,00 & - & $15,07 \mathrm{ab}$ \\
Plantmax & 17,80 & 14,30 & - & $16,05 \mathrm{bc}$ \\
Papel & 17,75 & 15,16 & - & $16,46 \mathrm{c}$ \\
\hline Média & $17,18 \mathrm{~A}$ & $14,00 \mathrm{~B}$ & - & 15,74 \\
\hline DMS (Tukey) - S & 1.1139 \\
\hline DMS (Tukey) - T* & 0.5834 \\
* Médias seguidas de mesma letra, maiúsculas na linha e minúsculas na \\
coluna, não diferem entre si, pelo teste de Tukey, ao nível de 5\% de \\
probabilidade.
\end{tabular}

(Tabela 2), provavelmente devido ao menor contato estabelecido entre o substrato e a semente, o que proporciona baixa disponibilidade de água para a embebição.

O maior tempo médio de germinação de sementes de $O$. minor a $25^{\circ} \mathrm{C}$ também está relacionado com a redução na velocidade das diversas reações metabólicas em virtude da redução de temperatura (Okusanya, 1980). Da mesma maneira, o aumento do tempo médio para germinação em temperaturas mais baixas foi observado na germinação de sementes de Phoenix roebelenii O'Brien (Iossi et al., 2003)

A temperatura ideal para germinação de sementes, segundo Ramos \& Varela (2003), geralmente varia dentro da faixa de temperatura encontrada no local e na época ideal para a emergência e estabelecimento das plântulas. E segundo Bewley \& Black (1994), a faixa de temperatura ótima é marcada pelo percentual mais alto de germinação, no menor tempo médio.

$\mathrm{O}$ menor tempo médio de germinação ocorreu a $30^{\circ} \mathrm{C}$ nos substratos areia e vermiculita (Tabelas 2). Da mesma forma, sementes de Phoenix roebelenii O’Brien germinaram mais rapidamente a $30^{\circ} \mathrm{C}$, nos substratos areia e esfagno (Iossi et al., 2003).

Profundidades de semeadura de 0 e $2 \mathrm{~cm}$ proporcionaram maiores porcentagens de emergência de plântulas de $O$. minor do que a profundidade de $4 \mathrm{~cm}$ (Tabela 3 ). O menor tempo médio de emergência de plântulas foi observado a $0 \mathrm{~cm}$ de profundidade de semeadura (Tabela 3).

As semeaduras em 2 e $4 \mathrm{~cm}$ de profundidade limitam e retardam a emergência de plântulas de bacabinha, pois semeaduras profundas dificultam a emergência das plântulas e aumentam o período de suscetibilidade a patógenos (Napier, 1985).

$\mathrm{Na}$ Tabela 4, os parâmetros avaliados confirmam que as profundidades menores do que $2 \mathrm{~cm}$ de semeadura são ideais, pois as plântulas possuem maior altura, espessura do colo e massa de matéria seca.

De acordo com Schmidt (1974) e Passos \& Ferreira (1991), a profundidade ideal de semeadura é a que garante uma germinação

TABELA 3 - Porcentagem (PE) e tempo médio de emergência (TME) de plântulas de $O$. minor, aos 60 dias após a semeadura em diferentes profundidades.

\begin{tabular}{cccc}
\hline & \multicolumn{3}{c}{ PE (\%) } \\
\hline \multirow{2}{*}{ Profundidade (cm) } & $\mathbf{0}$ & $\mathbf{2}$ & $\mathbf{4}$ \\
\cline { 2 - 4 } & $84.38 \mathrm{a}$ & $81.25 \mathrm{a}$ & $50.08 \mathrm{~b}$ \\
\hline Coeficiente de Variação - CV (\%) & \multicolumn{3}{c}{9.40} \\
\hline & TME (Dias) \\
\hline \multirow{2}{*}{ Profundidade (cm) } & $\mathbf{0}$ & $\mathbf{2}$ & $\mathbf{4}$ \\
\cline { 2 - 4 } & $41.00 \mathrm{a}$ & $53.14 \mathrm{~b}$ & $58.00 \mathrm{c}$ \\
\hline CV (\%) & \multicolumn{3}{c}{3.14} \\
\hline
\end{tabular}

*Médias diferentes seguidas da mesma letra, na linha, não diferem entre si, pelo teste de Tuckey, ao nível de 5\% de probabilidade.
TABELA 4 - Altura (A), espessura do colo (EC) e massa de matéria seca (MMSP) de plântulas de $O$. minor aos 60 dias após a semeadura em diferentes profundidades.

\begin{tabular}{ccccc}
\hline $\begin{array}{c}\text { Parâmetros } \\
\text { Avaliados/Profundidade } \\
(\mathbf{c m})\end{array}$ & $\mathbf{0}$ & $\mathbf{2}$ & $\mathbf{4}$ & $\begin{array}{c}\mathbf{C V} \\
\mathbf{( \% )}\end{array}$ \\
\hline $\mathbf{A ~ ( \mathbf { c m } )}$ & $6.28 \mathrm{a}$ & $4.93 \mathrm{~b}$ & $2.84 \mathrm{c}$ & 19.4 \\
\hline $\mathbf{E C ~ ( c m ) ~}$ & $0.347 \mathrm{a}$ & $0.233 \mathrm{~b}$ & $0.217 \mathrm{~b}$ & 10.7 \\
\hline MMSP(g) & $0.226 \mathrm{a}$ & $0.210 \mathrm{ab}$ & $0.192 \mathrm{~b}$ & 12.6 \\
\hline
\end{tabular}

"Médias diferentes seguidas da mesma letra, na linha, não diferem entre si, pelo teste de Tuckey, ao nível de 5\% de probabilidade.

homogênea das sementes, rápida emergência das plântulas e produção de mudas vigorosas.

\section{CONCLUSÕES}

1) Os substratos mais adequados para a germinação de sementes de $O$. minor são a areia e a vermiculita.

2) A temperatura ótima para a germinação de sementes de O. minor é de $30^{\circ} \mathrm{C}$.

3) Profundidade de semeadura superior a $2 \mathrm{~cm}$ são inadequadas para a emergência de plântulas de Oenocarpus minor Mart.

\section{REFERÊNCIAS}

ANDRADE, A.C.S.; LOUREIRO, M.B.; SOUZA, A.D.O.; RAMOS, F.N.; CRUZ, A.P.M. Reavaliação de efeito de substrato e da temperatura na germinação de sementes de palmiteiro (Euterpe edulis Mart.). Revista Árvore, Viçosa, v. 23, n. 3, p.279-283. 1999.

BENINCASA, M.M.P. Análise de crescimento de plantas: noções básicas. 2.ed. Jaboticabal: FUNEP, 2003. 41p.

BEWLEY, J.D.; BLACK, M. Seed physiology of development and germination. 2. ed. New York: Plenum Press, 1994. 657p.

BRASIL. Ministério da Agricultura e Reforma Agrária. Regras para análise de sementes. Brasília : LAVARV/ SNAD, 1992.365p.

CALZAVARA, B.B.G. As possibilidades do açaizeiro no estuário amazônico. Belém: Faculdade de Ciências Agrárias do Pará, 1978. 103p. (Boletim Técnico, 5)

CLEMENT, C.R.; BOVI, M.L.A. Padronização de medidas de crescimento e produção em experimento com pupunheiras para palmito. Acta Amazonica, Manaus, v. 30, n. 3, p. 349-362. 2000.

CLEMENT, C.R; MÜLLER, C.H.; FLORES, W.B.C. Recursos genéticas de espécies frutíferas da Amazônia Brasileira. Acta amazonica, Manaus, v.12, n. 4, p.677-695, 1982.

FERREIRA, C.A.G. Recuperação de áreas degradadas. Informe Agropecuário, Belo Horizonte, v. 21, n. 202, p.127-130, 2000.

FERREIRA, S.A.N.; SANTOS, L.A. dos. Efeito da velocidade de secagem sobre a emergência e vigor de sementes de pupunha (Bactris gasipaes Kunth). Acta Amazonica, Manaus, v. 23, n. 1, p.3-8, 1993.

FIGLIOLIA, M.B.; PIÑA-RODRIGUES, F.C.M. Considerações práticas sobre testes de germinação. In: SILVA, A.; PIÑA-RODRIGUES, F.C.M.; FIGLIOLIA, M.B. Manual técnico de sementes florestais. São Paulo: Instituto Florestal, 1995. p.1-12. (Série Registros, 14).

FIGLIOLIA, M.B; OLIVEIRA, E.C.; PIÑA-RODRIGUES, F.C.M. Análise de sementes. In: AGUIAR, I.B.; PIÑA-RODRIGUES, F.C.M.; FIGLIOLIA, M.B. (Ed). Sementes florestais tropicais. São Paulo: ABRATES, 1993. p.45-60.

GOMES, F. P. Curso de estatística experimental. São Paulo: Nobel, 1987.467p.

HACKBART, V. C. S.; CORDAZZO, C. V. Ecologia das sementes e estabelecimento das plântulas de Hydrocotyle bonariensis Lam. Atlântica, Rio Grande, n. 25, v. 1, p. 61-65, 2003. 
HENDERSON, A.; SCARIOT, A. A flórula da Reserva Ducke, I: Palmae (Arecaceae). Acta Amazonica, Manaus, v. 23, n. 4, p.349-369. 1993.

IOSSI, E.; SADER, R.; PIVETTA, K.F.L.A; BARBOSA, J.C. Efeitos de substratos e temperaturas na germinação de sementes de tamareira-anã (Phoenix roebelenni O'Brein). Revista Brasileira de Sementes, Brasília, v.25, n. 2, p.63-69, 2003.

LABOURIAU , L. G.; PACHECO, A. On the frequency of isothermal germination in seeds of Dolichos biflorus L. Plant and Cell Physiology, Oxford, v.19, n. 3, p. 507-512 1978.

LABOURIAU, L. G. A germinação das sementes. Washington: Secretaria Geral da Organização dos Estados Americanos, 1983. $174 \mathrm{p}$.

LABORIAU, L. G.; AGUDO, M. On the physiology of seed germination in Salvia hispanica L. I. Temperature Effects. Anais da Academia Brasileira de Ciências, Rio de Janeiro, n.59, p.37-56. 1987.

LEDO, A.S.; MEDEIROS-FILHO, S.; LEDO, F.J.S.;ARAÚJO, E.C. Efeito do tamanho de semente, do substrato e pré-tratamento em sementes de pupunha. Ciência Agronômica, Fortaleza, v.33, n. 1, p.29-32, 2002.

LORENZI, H.; SOUZA, H.M.; MEDEIROS-COSTA, J.T.; CERQUEIRA, L.S.C.; BEHR, N. Palmeiras no Brasil: nativas e exóticas. Nova Odessa: Plantarum, 1996. 303 p.

MARTINS, C.C.; NAKAGAWA, J.; BOVI, M.L.A. Efeito da posição da semente no substrato e no crescimento inicial das plântulas de Palmito-Vermelho (Euterpe espiritosantensis Fernandes - Palmae). Revista Brasileira de Sementes, Brasília, v. 21, n. 1, p. 164-173, 1999.

MIRANDA, I.P.A.; RABELO, A.; BUENO, C.R.; BARBOSA, E.M.; RIBEIRO, M.N.S. Frutos de Palmeiras da Amazônia. Manaus: MCT/INPA, 2001. 120p.
OKUSANYA, O. T. Germination and growth of Celosia cristata L. under various light and temperature regimes. American Journal of Botany, Columbus, v. 67, n. 6, p.854-858. 1980.

PASSOS, M.A.A.; FERREIRA, R.L.C. Influência da cobertura de semeio na emergência e desenvolvimento inicial de algaroba. Revista Brasileira de Sementes, Brasília, v. 13, n. 2: p.151-153, 1991.

PAULA, J.E.; ALVES, J.L.H. Madeiras Nativas: anatomia, dendrologia, dendrometria, produção e uso. Brasília: Fundação Mokiti Okada/ MOA, 1997.543p.

PINHEIRO, C.U.B. Germinação de sementes de palmeiras: Revisão Bibliográfica. Teresina: EMBRAPA - UEPAE, 1986. 102p.

QUEIROZ, M.H. Botão germinativo do palmiteiro como indicador de germinação. Revista Brasileira de Sementes, Brasília, n. 2, p.5559, 1986.

RAMOS, M.B.P.; VARELA, V.P. Efeito da temperatura e do substrato sobre a germinação de sementes de visgueiro do igapó (Parkia discolor Benth) LEGUMINOSAE, MIMOSOIDEAE. Revista de Ciências Agrárias, Belém, n. 39, p.135-143, 2003.

SCHMIDT, P.B. Sobre a profundidade ideal de semeadura do mogno (aguano) Swietenia macrophylla King. Brasil Florestal, Brasília. v.5, n.17, p.42-47. 1974.

SILVA, A.F.; OLIVEIRA,. R.V.; SANTOS, N.R.L.; PAULA, A. Um trecho de floresta semidecídua submontana da Fazenda São Geraldo, Viçosa-MG. Revista Árvore, Viçosa, v.27, n.3, p.311-319, 2003.

SOUZA, A. D. O.; ANDRADE, A. C. S.; LOUREIRO, M. B. Efeito do substrato e da temperatura na germinação de sementes de palmiteiro (Euterpe edulis Mart.). Informativo Abrates, Goiânia, v. 5, n. 2, p.190, 1995.

TOMLINSON, P.B. Anatomy of the monocotyledons: II Palmae. London: Oxford University, 1961. 